\title{
JUDICIALIZAÇÃO DA SAÚDE E ORÇAMENTO PÚBLICO
}

\author{
JUDICIALIZATION OF HEALTH AND PUBLIC BUDGET
}

\author{
Adriana Timoteo dos Santos Zagurski \\ Pontifícia Universidade Católica do Paraná - PUCPR - Curitiba - Paraná - Brasil \\ Danielle Anne Pamplona \\ Pontifícia Universidade Católica do Paraná - PUCPR - Curitiba - Paraná - Brasil
}

\begin{abstract}
Resumo: A crescente demanda por decisões judiciais para dirimir questões sociais levou ao Poder Judiciário temas antes restritos aos demais Poderes. Muitas críticas dirigidas a esse fenômeno fundamentam-se nos custos financeiros advindos de decisões judiciais proferidas sem conhecer a política pública desenvolvida pelo órgão do Executivo e os gastos já efetuados ou contemplados em leis orçamentárias. Nesse particular, utilizando-se de pesquisa documental, o artigo analisa a legislação aplicável - em especial a Emenda Constitucional no29/2000e Lei Complementar o 141/2012 que determinam aplicação de verbas do governo em saúde - buscando verificar se tais dispositivos são efetivamente cumpridos.
\end{abstract}

Palavras-chave: Direito à Saúde; Emenda Constitucional no 29/2000; Judicialização; Lei Complementar no 141/2012; Orçamento.

Abstract: The growing demand for judicial decisions that resolve social issues leading to the Judiciary themes previously restricted to other branches. Many criticisms of this phenomenon are founded on the financial costs arising from judicial decisions without knowing the public policy developed by the executive organ and expenditures already made or contemplated in budget laws. In this regard, using documentary research, the article analyzes the relevant legislation - particularly the Constitutional Amendment 29/2000 and Complementary Law No. 141/2012 that determine government funding application in health - seeking to verify if such devices are effectively met.

Keywords: Right to Health; Constitutional Amendment No. 29/2000; Judicialization; Complementary Law No. 141/2012, Budget. 


\title{
1. Introdução
}

O modo como estão estruturados os sistemas de saúde pública em diferentes Estados são indicativos do grau de proteção social que cada Estado provê e dos desafios de garantir-se o direito social à saúde.

Essa assertiva remonta ao período Pós-Guerra quando o Estado voltouse para a realização dos direitos fundamentais, buscando atenuar as diferenças sociais advindas da época de industrialização e do surgimento de trocas com base no capitalismo. Segundo Ana Luiza D'Ávila Viana e Cristiani Vieira Machado (2008):

\begin{abstract}
A forma criada para proteger os cidadãos desses movimentos de produção de desigualdades e de insegurança social foi a assunção pelo Estado, principalmente após a Segunda Guerra Mundial, do financiamento e provisão de um grande número de bens e serviços que os cidadãos não poderiam acessar única e exclusivamente pela renda obtida pelo trabalho, ou quando sem trabalho necessitassem desses bens, como é o caso da saúde.
\end{abstract}

E prosseguem as autoras alertando que

a política de saúde se insere fortemente nesse movimento de subtrair da órbita mercantil o acesso aos bens e serviços de saúde, quando a responsabilidade pela saúde de uma determinada população passa a ser responsabilidade de todos, coletiva, e um direito do cidadão (VIANA; MACHADO, 2008).

Essa preocupação tem se traduzido em diversas legislações no âmbito interno e externo. No âmbito internacional, o órgão que lidera as ações voltadas aos diversos aspectos que envolvem a saúde, como prevenção de doenças ou ações imediatas diante de crises, é a Organização Mundial da Saúde. Seus trabalhos estão estruturados por meio da divisão das prioridades por assuntos. Há, assim, seis grandes temas prioritários para suas ações. A cobertura sanitária universal é um deles, e nela são desenvolvidas ações de pesquisa e sugestões para que todas as pessoas possam ter acesso aos serviços necessários para ter uma saúde boa, assim como tenham acesso à proteção financeira para prevenir problemas de saúde, reconhecendo que estes podem, inclusive, levar à pobreza. Em relação à regulamentação sanitária internacional, este organismo se preocupa em auxiliar os países a

Revista do Direito UNISC, ISSN: 1982-9957

Santa Cruz do Sul №. 48 | p. 92-117 | JAN-ABR 2016

https://online.unisc.br/seer/index.php/direito/index 
realizar as capacidades prescritas no Regulamento Sanitário Internacional, em especial em relação às emergências da saúde pública. A organização Mundial da Saúde também se ocupa, prioritariamente, com o acesso à medicamentos e com respostas adequadas às chamadas doenças não transmissíveis, como cardiopatias e câncer.

Outro setor prioritário é aquele que se ocupa de trabalhar com outros setores dentro dos Estados para atacar as questões econômicas, sociais e ambientais que podem afetar a saúde. Por fim, a última área prioritária é a que trabalha com os objetivos de desenvolvimento do milênio relacionados à saúde, em especial com a construção de sistemas de saúde robustos e instituições sanitárias eficientes.

No âmbito interno, destaca-se a adoção de uma Agenda 21 Interna ${ }^{1}$, que traduz um esforço do Estado brasileiro e de vários setores da sociedade para atingir um desenvolvimento sustentável. No Brasil, a Agenda 21 trata especificamente do tema saúde, alertando que saúde e desenvolvimento estão intimamente relacionados:

Tanto um desenvolvimento insuficiente que conduza à pobreza como um desenvolvimento inadequado que resulte em consumo excessivo, associados a uma população mundial em expansão, podem resultar em sérios problemas para a saúde relacionados ao meio ambiente, tanto nos países em desenvolvimento como nos desenvolvidos. Os tópicos de ação da Agenda 21 devem estar voltados para as necessidades de atendimento primário da saúde (...) (ONU, 1992).

De fato, verifica-se que países desenvolvidos e em desenvolvimento investem parcela considerável do seu PIB no setor de saúde. O Brasil, segundo o Instituto Brasileiro de Geografia e Estatística (IBGE), tinha um dispêndio total (público e privado) em saúde equivalente a 8,8\% do PIB em 2012 (ENSP, 2012).

No entanto, esse número é inferior ao estabelecido pela legislação brasileira. A Emenda Constitucional n 29/2000 e a Lei Complementar no

\footnotetext{
${ }^{1}$ A Agenda 21 é um documento aprovado na reunião Conferência das Nações Unidas para o Meio Ambiente e Desenvolvimento, chamada Eco-92, envolvendo vários temas e seu tratamento para concretização do desenvolvimento sustentável. Em 1997 foi criada a Agenda 21 Brasileira, com o objetivo de firmar compromissos da sociedade brasileira com 0 desenvolvimento.
}

Revista do Direito UNISC, ISSN: 1982-9957

Santa Cruz do Sul №. 48 | p. 92-117 | JAN-ABR 2016

https://online.unisc.br/seer/index.php/direito/index 
141/2012 determinam um investimento maior, que possa traduzir, na prática, o acesso universal ao direito à saúde.

As deficiências na prestação do serviço público de saúde, a falta de estrutura e investimentos no setor, entre outros fatores ${ }^{2}$, geram questionamentos judiciais que precisam de uma análise mais detida se 0 objetivo é verificar o efetivo cumprimento da legislação e as respostas dadas pelo Poder Judiciário.

Com esse objetivo o texto será organizado em quatro seções incluindo esta introdução; a segunda analisa a legislação aplicável ao direito fundamental à saúde, destacando as Emendas Constitucionais já referidas; a terceira aborda a judicialização envolvendo políticas públicas de saúde no Brasil e a terceira traz as considerações finais acerca da possibilidade de utilização da questão orçamentária como fundamento para decisões judiciais que tratam do tema.

\section{Legislação aplicável e o direito fundamental à saúde}

Face a fundamentalidade do direito à saúde, previsto no artigo 196 da Constituição Federal de 1988 - CF/88 - e, partindo da premissa de que as normas constitucionais devem ser cumpridas, outros dispositivos foram editados para regulamentar os gastos mínimos para efetivação desse direito.

A CF/88 determina que os serviços de saúde deveriam observar as diretrizes da universalidade e do atendimento integral e estabelece, em seu artigo 198, que a União, Estado e Municípios devem aplicar anualmente recursos em ações e serviços de saúde, todavia, deixa de definir os percentuais a serem aplicados, aí a justificativa para a existência de outros tipos legais que regulamentam a norma constitucional.

Diferentemente do que ocorreu com a educação, para a qual foi estipulado o montante mínimo das receitas resultantes de impostos que União,

\footnotetext{
${ }^{2} \mathrm{~A}$ doutrina discute sobre os reais motivos que levam ao fenômeno da proposição de muitas ações judiciais sobre temas que antes não chegavam ao judiciário. Ver NATAL, Mariane; PAMPLONA, Danielle Anne. 0 papel político do judiciário em políticas públicas: a judicialização da política e a democracia, p. 132 e ss.

Revista do Direito UNISC, ISSN: 1982-9957

Santa Cruz do Sul №. 48 | p. 92-117 | JAN-ABR 2016

https://online.unisc.br/seer/index.php/direito/index
} 
Estados e Municípios devem aplicar nesta área ${ }^{3}$, o direito à saúde não mereceu o mesmo tratamento. A falta de parâmetros mínimos constitucionais gera a não realização de uma política ostensiva de saúde.Com o desafio de mudar esse quadro fático, foi editada a Emenda Constitucional oㅡ 29/2000 que altera os artigos 34, 35, 156, 160, 167 e 198 da Constituição Federal e acrescenta artigos ao Ato das Disposições Constitucionais Transitórias para assegurar os recursos mínimos ao financiamento das ações e serviços públicos de saúde.

Segundo Magali Campelli e Maria Cristina Calvo (2007):

\begin{abstract}
A EC-29, ou Emenda Constitucional da Saúde, foi criada com 0 objetivo de evitar a repetição dos problemas que comprometeram 0 financiamento do Sistema Único de Saúde (SUS) nos anos 90. Nessa década não havia um parâmetro legal que obrigasse os Estados, Distrito Federal e municípios a destinarem recursos próprios para a área de saúde; a economia e as políticas públicas das fontes de financiamento no âmbito da União para financiar o SUS eram instáveis e sempre se adotavam medidas emergenciais e provisórias para fazer frente à falta de recursos para o setor.
\end{abstract}

Dispõe a Emenda Constitucional o 29 de 13 de setembro de 2000:

O Ato das Disposições Constitucionais Transitórias passa a vigorar acrescido do seguinte Art.77:

Art.77 - Até o exercício financeiro de 2004, os recursos mínimos aplicados nas ações e serviços públicos de saúde serão equivalentes: (AC)

I - no caso da União: (AC)

a) no ano 2000, o montante empenhado em ações e serviços públicos de saúde no exercício financeiro de 1999 acrescido de, no mínimo, cinco por cento; $(A C)$

b) do ano 2001 ao ano 2004, o valor apurado no ano anterior, corrigido pela variação nominal do Produto Interno Bruto - PIB; (AC)

II - no caso dos Estados e do Distrito Federal, doze por cento do produto da arrecadação dos impostos a que se refere o Art.155 e dos recursos de que tratam os Arts.157 e 159, inciso I, alínea a, e inciso II, deduzidas as parcelas que forem transferidas aos respectivos Municípios; e (AC)

III - no caso dos Municípios e do Distrito Federal, quinze por cento do produto da arrecadação dos impostos a que se refere o Art.156 e dos recursos de que tratam os Arts 158 e 159, inciso I, alínea b e $3^{\circ}$ $(\mathrm{AC})$.

§1․ Os Estados, o Distrito Federal e os Municípios que apliquem percentuais inferiores aos fixados nos incisos II e III deverão elevá-los gradualmente, até o exercício financeiro de 2004, reduzida a diferença à razão de, pelo menos, um quinto por ano, sendo que, a partir de 2000, a aplicação será de pelo menos sete por cento. (AC)

$\S 2^{\circ}$. Dos recursos da União apurados nos termos deste artigo, quinze por cento, no mínimo, serão aplicados nos Municípios, segundo o

\footnotetext{
${ }^{3}$ De acordo com o artigo 212 da CF/88 a União deve aplicar ao menos $18 \%$ e os Estados e
} Municípios, 25\%.

Revista do Direito UNISC, ISSN: 1982-9957

Santa Cruz do Sul №. 48 | p. 92-117 | JAN-ABR 2016

https://online.unisc.br/seer/index.php/direito/index 
critério populacional, em ações e serviços básicos de saúde, na forma da lei. (AC)

§3‥ Os recursos dos Estados, do Distrito Federal e dos Municípios destinados às ações e serviços públicos de saúde e os transferidos pela União para a mesma finalidade serão aplicados por meio de Fundo de Saúde que será acompanhado e fiscalizado por Conselho de Saúde, sem prejuízo do disposto no Art.74 da Constituição Federal".

§4․ Na ausência da lei complementar a que se refere o art. 198, §3ํㅡ, a partir do exercício financeiro de 2005, aplicar-se-á à União, aos Estados, ao Distrito Federal e aos Municípios o disposto neste artigo.

Desde a sua edição, diversos estudos demonstraram que a Emenda não vinha sendo cumprida pelos órgãos do executivo em várias esferas. Campelli e Calvo (2007), analisaram o período de 2000 a 2003 e verificaram que a União não cumpriu a Emenda e que naquele período, deixou de aplicar em saúde um valor acumulado de $\mathrm{R} \$ 1,8$ bilhão. Em relação aos estados da federação, prosseguem afirmando que:

(...) no ano 2000, 11 Estados não cumpriram a EC-29, o que representou um passivo de $R \$ 0,88$ bilhão. No ano de 2001 , esse número aumentou para 18, e deixaram de ser aplicados em saúde $R \$$ 1,08 bilhão. Em 2002, foram 16 Estados, representando um passivo de $R \$ 1,66$ bilhão. Em 2003, 13 Estados deixaram de cumprir 0 mínimo exigido pela EC-29, o que representa a não aplicação de recursos financeiros na ordem de $R \$ 1,67$ bilhão. $O$ déficit acumulado até 2003 representa uma dívida de $R \$ 5,29$ bilhões com o SUS (BRASIL, 2005). ${ }^{4}$

Já nos anos de 2006 e 2007, auditoria realizada pelo DenaSUS Departamento Nacional de Auditoria do SUS - revelou que dezesseis (16) Estados em 2006 e dezessete (17) em 2007 não cumpriram a Emenda aplicando percentual abaixo do mínimo de $12 \%$ e "como consequência disso, o montante não aplicado em saúde nos Estados atingiu $R$ \$ 5.986 bilhões e $R \$$ 6.053 bilhões nos anos de 2006 e 2007, cujos valores atualizados para junho de 2010 são de $R \$ 7.558$ bilhões e $R \$ 7.321$ bilhões, respectivamente" (CNS Conselho Nacional de saúde, 2010).

Em outro estudo, Mauricio Correia da Silva et al (2012), analisaram a aplicação em saúde nos cem municípios mais populosos do Brasil no período de 2000 a 2008 e, deste montante, verificou-se que quarenta e nove não

\footnotetext{
${ }^{4}$ No mesmo ano, segundo o site do Ministério da Saúde, onze (11) Estados cumpriram a emenda 29/2000: AC, AM, AP, PA, RO, RR, TO, BA, RN, SE, SP e dezesseis (16) Estados não cumpriram: AL, CE, MA, PB, PE, PI, ES, MG, RJ, PR, RS, SC, DF, GO, MS, MT.

Revista do Direito UNISC, ISSN: 1982-9957

Santa Cruz do Sul №. 48 | p. 92-117 | JAN-ABR 2016

https://online.unisc.br/seer/index.php/direito/index
} 
cumpriram em determinado ano os percentuais vinculatórios de gastos com saúde.

Outro problema verificado diante da ausência de regulamentação da Emenda foi a inclusão pelos governos na conta da saúde de gastos como saneamento, fundos para pagamento de pessoal e programas sociais. Sobre esse procedimento, transcreve-se a propósito, os dizeres de Silva e Rotta (2012):

\begin{abstract}
ressalta-se ainda a confusa, eloquente e oportunista ideia dos governantes de discriminar recursos para outras ações e serviços públicos com orçamento da saúde, incluindo gastos das ações e serviços da saúde, despesas com inativos, com saneamento, habitação urbana, recursos hídricos, merenda escolar, programas de alimentação e hospitais de clientela fechada, para atingirem as metas de aplicação.
\end{abstract}

Apesar desse quadro fático, verificou-se um aumento no valor gasto per capita das três esferas de governo com o SUS: dobrou entre 2000 e 2011, passando de $R \$ 403,00$ em 2000 para $R \$ 830,00$ em 2011 e em relação ao PIB, o gasto do SUS passou de 2,9\%, em 2000, para 3,9\% em 2011.

E os valores ainda estão abaixo do determinado pela EC 29/2000. Segundo Sergio Francisco Piola e outros "o aporte de recursos poderia ter sido ainda maior, caso a União e os estados cumprissem a EC 29 de acordo com os critérios previstos na Resolução 322 do CNS. O Governo Federal e os governos estaduais utilizaram diversos expedientes para aplicar menos do que o previsto na Emenda" (PIOLA, 2013).

Os valores são previstos nos orçamentos, porém, são posteriormente cancelados ou são postergados nos chamados restos a pagar, o problema é em que proporção isso ocorre e se isso era utilizado para cumprir a vinculação só no papel (PIOLA, 2013).

Assim, apesar da EC 29/2000 ser considerada um avanço, segundo levantamento do Conselho Federal de Medicina (CFM), dos R\$47,3 bilhões gastos com investimentos pelo Governo Federal em 2013, o Ministério da Saúde foi responsável por apenas $8,2 \%$ dessa quantia. Ainda segundo o mesmo Conselho, em 13 anos, $\mathrm{R} \$ 47$ bilhões deixaram de ser investidos pois nos últimos 12 anos (2001 a 2013), foram autorizados $R \$ 80,5$ bilhões específicos para este fim, no entanto, apenas $R \$ 33$ bilhões foram efetivamente 
gastos e outros $R \$ 47,5$ bilhões deixaram de ser investidos. Em outras palavras, de cada $R \$ 10$ milhões previstos para a melhoria da infraestrutura em saúde, $R$ \$ 6 milhões deixaram de ser aplicados.

Para exemplificar, o presidente do CFM, afirma:

\begin{abstract}
com $\mathrm{R} \$ 47,5$ bilhões, seria possível adquirir 386 mil ambulâncias (69 para cada município brasileiro); construir 237 mil Unidades Básicas de Saúde (UBS) de porte I (43 por cidade); edificar 34 mil Unidades de Pronto Atendimento (UPA) de porte I (seis por cidade) ou, ainda, aumentar em 936 o número de hospitais públicos de médio porte. "Sabemos que esse dinheiro não seria aplicado todo em uma única ação, mas pela comparação com o que se poderia fazer, tomamos consciência do tamanho do desperdício (CFM - Conselho Federal de Medicina, 2014).
\end{abstract}

Após 12 anos, em 13 de janeiro de 2012 foi regulamentada a EC 29/2000 com a edição da Lei Complementar no 141 - LC 141/2012 - que regulamenta o $\S 3^{\circ}$ do art. 198 da Constituição Federal para dispor sobre os valores mínimos a serem aplicados anualmente pela União, Estados, Distrito Federal e Municípios em ações e serviços públicos de saúde; estabelece os critérios de rateio dos recursos de transferências para a saúde e as normas de fiscalização, avaliação e controle das despesas com saúde nas 3 (três) esferas de governo; revoga dispositivos das Leis $\mathrm{n}^{\circ} \mathbf{8 . 0 8 0}$, de 19 de setembro de 1990, e 8.689, de 27 de julho de 1993.

A LC nำ 141/2012 não apresentou qualquer vinculação de recursos federais para a saúde, frustrando a expectativa de ampliação de recursos para o setor. Municípios devem aplicar $15 \%$ de suas receitas em saúde; os Estados $12 \%$ de suas receitas tributárias e a União deve aplicar, no mínimo, o montante correspondente ao valor empenhado no exercício financeiro anterior acrescido do percentual correspondente à variação nominal do PIB ocorrida no ano anterior ao da lei orçamentária anual.

Outra importante inovação diz respeito a definição do que são gastos com saúde e, por consequência, daqueles que não podem ser considerados como despesas com ações e serviços públicos de saúde, para fins de apuração dos percentuais mínimos de que trata a Lei Complementar. Nesse sentido, será o artigo 4ํ da LC 141/2012 que expressamente prevê um longo rol de despesas que não podem ser consideradas como de saúde, dentre elas as despesas decorrentes de pagamento de aposentadorias e pensões; de 
assistência à saúde que não atenda ao princípio de acesso universal ou de merenda escolar.

Segundo relatório do TCU - Tribunal de Contas da União, nos exercícios de 2011 e 2012 em cumprimento ao disposto constitucionalmente, o Ministério da Saúde executou $R$ \$ 72,35 bilhões e $R \$ 80,07$ bilhões no custeio da saúde, respectivamente. Verifica-se que houve um incremento de 10,67\% no orçamento da saúde em 2012. Considerando o que dispõe o art. 5ํ da Lei Complementar no 141/2012 e que a variação nominal do PIB foi de 9,89\% em relação ao exercício anterior, conclui-se que a União empenhou recursos suficientes para cumprir a regra de aplicação mínima de recursos no Setor Saúde (BRASIL, TCU, 2013).

No entanto, segundo o mesmo relatório:

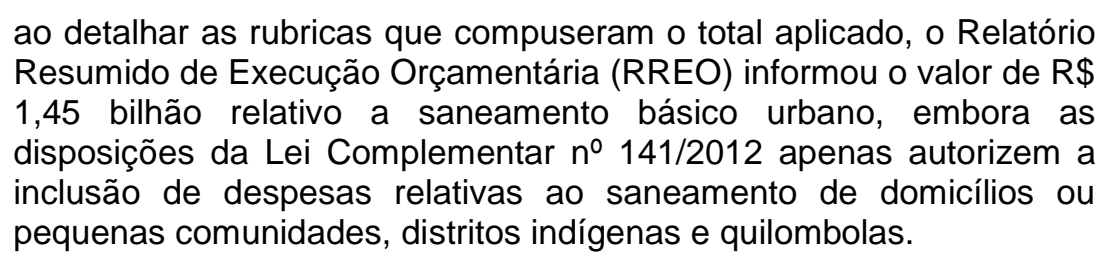

E ainda, entre 2008 e 2012, R\$ 20,4 bilhões, em valores atualizados, deixaram de ser aplicados na Função Saúde, em relação ao que foi previsto nos orçamentos da União, sendo $R \$ 9,6$ bilhões somente em 2012. (BRASIL, TCU, 2013).

Segundo estudo divulgado Fundação Oswaldo Cruz, concluiu-se que em 2013:

ainda que a EC 29/2000 tenha sido regulamentada, há vários indicativos de ampliação dos subsídios públicos ao setor privado, sem aumento significativo de recursos públicos para a saúde de caráter universal. Desta forma este último cenário mostra-se cada vez mais distante e exigirá um reforço continuado da luta política em favor do aumento de recursos públicos para o SUS e restrição à ampliação dos incentivos públicos ao setor privado (PIOLA, 2013).

De tudo que foi exposto, pode-se afirmar que, de modo geral, os governos em todas as esferas não vêm cumprindo o disposto nas emendas sobre a saúde abrindo-se a possibilidade de intervenção pelo Poder Judiciário sobre esta questão. Ora, se a CF/88 não é observada, cumpre a esse Poder, 
quando demandado, pronunciar-se de modo a concretizar os ditames constitucionais. É sobre essa questão que se discorre a seguir.

\section{Judicialização e políticas públicas de saúde}

Como já dito acima, o texto constitucional não pode ser mera promessa e assim, os direitos fundamentais sociais ali previstos devem ser concretizados, em outras palavras, a constitucionalização de direitos implica na sua eficácia. Em se tratando do direito à saúde, o meio para sua concretização está especialmente previsto no art. $216 \mathrm{CF} / 88$ : as políticas públicas.

Celina Souza após analisar a gênese do termo e os principais autores que tratam do tema, conceitua políticas públicas como:

\footnotetext{
o campo do conhecimento que busca, ao mesmo tempo, "colocar o governo em ação" e/ou analisar essa ação (variável independente) e, quando necessário, propor mudanças no rumo ou curso dessas ações (variável dependente). A formulação de políticas públicas constitui-se no estágio em que os governos democráticos traduzem seus propósitos e plataformas eleitorais em programas e ações que produzirão resultados ou mudanças no mundo real (Souza, 2006).
}

Num regime democrático, a decisão e formulação de políticas públicas compete aos chamados atores sociais estatais em conjunto com os privados (oriundos da sociedade civil como trabalhadores, sindicatos, empresários, meios de comunicação), não sendo este o papel principal do Judiciário, ainda que se admita sua influência na deliberação e implementação de políticas públicas (TAYLOR, 2007).

Por outro lado, sob a justificativa da omissão ou ineficiência dos demais poderes e com fundamento no artigo $5^{\circ}$ inciso XXXV da $\mathrm{CF} / 88$, que dispõe sobre o princípio da inafastabilidade da jurisdição, muitas ações têm sido propostas no Judiciário para questionar a execução e implementação de políticas públicas. Assim, nasce o fenômeno da judicialização da política, "a crescente confiança em cortes e meios judiciais para resolver problemas 
essencialmente morais, questões de políticas públicas e controvérsias políticas". (HIRSCHL, p. 721)

De fato, "a atuação judicial na conformação das políticas públicas é imprópria, uma vez que a formulação das políticas públicas cabe, em regra, ao Poder Executivo" (PAMPLONA; ANDRADE, 2011). Assim, em caso de omissão ou ineficiência dos demais poderes, em especial o Executivo, a população recorre ao Poder Judiciário para que intervenha também no âmbito das políticas públicas.

É justamente nesse sentido que o fenômeno denominado judicialização: uma crescente demanda por decisões judiciais para dirimir questões sociais e o consequente crescimento dos gastos públicos determinados por decisões judiciais.

A expressão judicialização tem sua origem na obra de C. N. Tate e T. Vallinder (1995), em que foram formuladas linhas de análise comuns para a pesquisa empírica comparada do Poder Judiciário em diferentes países.

Para Tate e Vallinder apud Barbosa (2013), a judicialização apresenta dois distintos significados:

(1) The expansion of the province of the court sorthe judges at the expense of the politicians and/orthe administrators, thatis, the transfer of decision-making rights from the legislature, the cabinet, or the civil service to the courts, or, at least; (2) The spread of judicial decisionmaking methods out side the judicial province proper. ${ }^{6}$

É no sentido do primeiro significado que o termo é utilizado no presente estudo.

A constitucionalização dos direitos sociais e a nova configuração da sociedade civil (LANGFORD, 2009) - apoiada em organizações de defesa de direitos humanos - trouxe consigo um aumento na quantidade de casos trazidos ao Judiciário, pois, sendo os direitos sociais uma obrigação estatal, a

\footnotetext{
${ }^{5}$ No original: "...the ever-accelerating reliance on courts and judicial means for addressing core more predicaments, public policy questions, and political controversies." Tradução livre das autoras.

6“(1) A competência das cortes e dos juízes, em detrimento dos políticos e dos administradores, quer dizer, a transferência do poder decisório do legislativo, do executivo ou da administração publica para as cortes ou, pelo menos, (2)a propagação dos métodos próprios de tomadas de decisão judicial para além da jurisdição apropriada".
}

Revista do Direito UNISC, ISSN: 1982-9957

Santa Cruz do Sul №. 48 | p. 92-117 | JAN-ABR 2016

https://online.unisc.br/seer/index.php/direito/index 
insuficiente atuação do poder público para tratar de temas como o direito à saúde pública, traz como conseqüência a judicialização dos mesmos.

Esse fenômeno remete à questão: é possível reclamar judicialmente diante do não cumprimento dos direitos sociais?

Enrique Del Carril em artigo onde comenta a justiciabilidade dos direitos econômicos, sociais e culturais, lembra que existem duas posturas extremas: as que negam aos direitos sociais a sua justiciabilidade e as que a admitem:

\begin{abstract}
No primeiro caso, diz-se que esses direitos são essencialmente diferentes dos "civis e políticos", que esta diferença é essencial e que lança por terra a possibilidade de sua reclamação judicial, porque, enquanto os direitos civis não reclamam do Estado mais do que uma atitude meramente passiva - a de não entorpecer o seu exercício -, os sociais impõem prestações concretas com vistas a serem efetivados. Por isso, estes últimos seriam "programáticos", isto é, pautas dirigidas aos órgãos políticos, mas que não podem ser reclamados perante os juízes. A partir de outra perspectiva, argumenta-se que não há uma diferença conceitual entre ambos, que tanto os direitos civis como os sociais exigem obrigações passivas e ativas, que sempre é preciso comprometer recursos financeiros estatais. Que todos os direitos supõem, ao menos, alguma dimensão justiciável. (CARRIL, 2011, p. 697)
\end{abstract}

Essa polêmica remonta às chamadas gerações de direitos e a prescindibilidade de prestações positivas do Estado que distinguiam os direitos civis e políticos dos direitos sociais ${ }^{7}$.

Sem aprofundar a discussão, pois não é o objetivo deste artigo, pode-se afirmar que os direitos sociais são exigíveis judicialmente tais como os direitos civis e políticos tendo em vista a relação existente entre ambos:

Só o reconhecimento integral de todos esses direitos pode assegurar a existência real de cada um deles, já que sem a efetividade de gozo dos direitos econômicos, sociais e culturais, os direitos civis e políticos se reduzem a meras categorias formais. Inversamente, sem a realidade dos direitos civis e políticos, sem a efetividade da liberdade entendida em seu mais amplo sentido, os direitos

\footnotetext{
7 Segundo Daniel Hachem os direitos de civis e políticos (de primeira geração) teriam "a condição de genuínos direitos subjetivos (públicos, porque oponíveis ao Estado), dotados de aplicação imediata e independente de lei integrativa, cuja satisfação total se alcançaria mediante uma ordem judicial de não fazer expendida ao Poder Público". Aos direitos sociais "faleceria o status de verdadeiros direitos subjetivos, na plenitude do termo. Embora pudessem ser reivindicados judicialmente, sua efetivação dependeria da existência de regulamentação infraconstitucional e de disponibilidade orçamentária. Careceriam de aplicabilidade imediata, portanto. (HACHEM, 2013, p. 621).
}

Revista do Direito UNISC, ISSN: 1982-9957

Santa Cruz do Sul №. 48 | p. 92-117 | JAN-ABR 2016

https://online.unisc.br/seer/index.php/direito/index 
econômicos, sociais e culturais carecem, por sua vez, de verdadeira significação. (ESPIELL apud PIOVESAN, 2004)

Ainda segundo Carril (2011, p. 716) esta relação "tem o seu fundamento último na unidade essencial do indivíduo". Os direitos civis e sociais vinculamse e se entrelaçam, "promovendo uns, promovem-se os outros". Um exemplo citado pelo autor é a forte relação entre o direito à vida e o direito à saúde e, este por sua vez, entendido como corolário lógico do exercício dos demais direitos fundamentais.

O protagonismo do Judiciário pode não ser a solução para a falta de acesso da população a bens e serviços, porém, deve-se admitir a reivindicação judicial uma vez que, de acordo com o comando legal, estes direitos possuem eficácia imediata. Nas palavras de Pilar Arcidiácono e Gustavo Gamallo: "la otra faceta de la obligación del Estado es la posibilidad de que los titulares de los derechos sociales puedan exigir su cumplimiento apelando a un tribunal de justicia." (2011, p. 71).

E novamente nesse ponto que se volta a questão do cumprimento da EC 29/2000 e LC 141/2012 pois,

a formulação e implementação de políticas públicas pelos Poderes
Executivo e Legislativo, notadamente aquelas destinadas a garantir
os chamados direitos de segunda dimensão (direitos econômicos,
sociais e culturais), depende, em grande parte, de opção política e de
disponibilidade orçamentária e financeira do Poder Público, o qual
poderá, em tese, se eximir de implementar total ou parcialmente tais
políticas em razão de falta ou insuficiência de recursos financeiros
(PEREIRA, 2010).

Surgem muitos questionamentos sobre a questão dos recursos e Estado frequentemente invoca sua insuficiência fazendo que se destaque, então, a teoria da reserva do possível que remete à ideia de custos dos direitos, onde o Estado estaria obrigado a prestações positivas dentro de uma disponibilidade financeira razoável.

Na sua origem alemã, a ideia da teoria seria que não se mostra razoável exigir mais do estado, para o fim de satisfação individual de cada cidadão, negligenciando outros programas sociais, ou mesmo comprometendo suas políticas públicas (OLSEN, 2006). Essa forma de pensar e sua transposição para a realidade brasileira foi criticada pelo Ministro Herman Benjamin, nos 
autos do Agravo Regimental no Recurso Especial no 1107511, afirmando que a importação alemã da teoria da reserva do possível deve ser analisada à luz da realidade social, econômica e política de nosso país:

\begin{abstract}
A teoria da reserva do possível, importada do Direito alemão, tem sido utilizada constantemente pela administração pública como escudo para se recusar a cumprir obrigações prioritárias.

Não deixo de reconhecer que as limitações orçamentárias são um entrave para a efetivação dos direitos sociais. No entanto, é preciso ter em mente que o princípio da reserva do possível não pode ser utilizado de forma indiscriminada.

$\mathrm{Na}$ verdade, o direito alemão construiu essa teoria no sentido de que o indivíduo só pode requerer do estado uma prestação que se dê nos limites do razoável, ou seja, na qual o peticionante atenda aos requisitos objetivos para sua fruição.

Informa a doutrina especializada que, de acordo com a jurisprudência da Corte Constitucional alemã, os direitos sociais prestacionais estão sujeitos à reserva do possível no sentido daquilo que o indivíduo, de maneira racional, pode esperar da sociedade (Krell. Andreas J. Controle judicial dos serviços públicos na base dos direitos fundamentais sociais in SARLET, Ingo Wolfgang (org.). A Constituição Concretizada - Construindo Pontes entre o Público e o Privado. 2000, p. 41). Ora, não se podem importar preceitos do direito comparado sem atentar para as peculiaridades jurídicas e sociológicas de cada país. A Alemanha já conseguiu efetivar os direitos sociais de forma satisfatória, universalizou o acesso aos serviços públicos mais básicos, o que permitiu um elevado índice de desenvolvimento humano de sua população, realidade ainda não alcançada pelo Estado brasileiro (BRASIL, 2013).
\end{abstract}

Também este é o entendimento do Supremo Tribunal Federal (STF) na Arguição de Descumprimento de Preceito Fundamental (BRASIL, ADPF 45/DF ${ }^{8}$ ): quando da inércia ou comportamento abusivo do Estado puder resultar lesão ou ameaça a direitos constitucionais fundamentais, sem motivo

\footnotetext{
${ }^{8}$ BRASIL. Supremo Tribunal Federal - STF. EMENTA: ARGÜIÇÃO DE DESCUMPRIMENTO DE PRECEITO FUNDAMENTAL. A QUESTÃO DA LEGITIMIDADE CONSTITUCIONAL DO CONTROLE E DA INTERVENÇÃO DO PODER JUDICIÁRIO EM TEMA DE IMPLEMENTAÇÃO DE POLÍTICAS PÚBLICAS, QUANDO CONFIGURADA HIPÓTESE DE ABUSIVIDADE GOVERNAMENTAL. DIMENSÃO POLÍTICA DA JURISDIÇÃO CONSTITUCIONAL ATRIBUÍDA AO SUPREMO TRIBUNAL FEDERAL. INOPONIBILIDADE DO ARBÍTRIO ESTATAL À EFETIVAÇÃO DOS DIREITOS SOCIAIS, ECONÔMICOS E CULTURAIS. CARÁTER RELATIVO DA LIBERDADE DE CONFORMAÇÃO DO LEGISLADOR. CONSIDERAÇÕES EM TORNO DA CLÁUSULA DA "RESERVA DO POSSÍVEL". NECESSIDADE DE PRESERVAÇÃO, EM FAVOR DOS INDIVÍDUOS, DA INTEGRIDADE E DAINTANGIBILIDADE DO NÚCLEO CONSUBSTANCIADOR DO "MÍNIMO EXISTENCIAL". VIABILIDADE INSTRUMENTAL DA ARGÜIÇÃO DE DESCUMPRIMENTO NO PROCESSO DE CONCRETIZAÇÃO DAS LIBERDADES POSITIVAS (DIREITOS CONSTITUCIONAIS DE SEGUNDA GERAÇÃO). Arguição de Descumprimento de Preceito Fundamental no 45/DF. PSDB - Partido da Social Democracia Brasileira. Relator Min. Celso de Mello. DJ 04/05/2004.Revista Trimestral de Jurisprudência - RTJ - vol. 200, p. 191. Disponível em: $<$ http://www.stf.jus.br/portal/jurisprudencia/listarJurisprudencia.asp?s1=\%28ADPF\%24\%2ESCL $\mathrm{A} \% 2 \mathrm{E}+\mathrm{E}+45 \% 2 \mathrm{ENUME} \% 2 \mathrm{E} \% 29$ \&base=basePresidencia\&url=http://tinyurl.com/a9kzfpa .
} Acesso em: 24 nov. 2014.

Revista do Direito UNISC, ISSN: 1982-9957

Santa Cruz do Sul №. 48 | p. 92-117 | JAN-ABR 2016

https://online.unisc.br/seer/index.php/direito/index 
objetivamente aferível, a cláusula da Reserva do Possível não poderá ser invocada, sob pena de provocação do Poder Judiciário. Assim, refuta-se o argumento da ausência de recursos ou escassez de recursos orçamentários.

Sobre possibilidade de intervenção do Poder Judiciário, Vanice Regina Lirio do Valle (2009) critica a atuação do juiz em relação à políticas públicas e no orçamento público sob vários argumentos: objeções atinentes ao déficit democrático (legitimação); no que tange a decisões que importem em (re)configuração do agir dos poderes compostos a partir do princípio representativo e as deficiências funcionais do Poder Judiciário para o controle ou redirecionamento das políticas públicas.

O próprio Judiciário, no entanto, já teve a oportunidade de se manifestar sobre sua legitimidade para tratar do assunto. O Ministro do Supremo Tribunal Federal, Celso de Mello, no julgamento do Recurso Extraordinário-RE 581352/ $\mathrm{AM}^{9}$ afirma que cabe ao Poder Judiciário cumprir a sua missão institucional:

\footnotetext{
${ }^{9}$ BRASIL. Supremo Tribunal Federal - STF. EMENTA: AMPLIAÇÃO E MELHORIA NO ATENDIMENTO DE GESTANTES EM MATERNIDADES ESTADUAIS - DEVER ESTATAL DE ASSISTEENCIA MATERNO-INFANTIL RESULTANTE DE NORMA CONSTITUCIONAL OBRIGAÇÃO JURÍDICO- -CONSTITUCIONAL QUE SE IMPÕE AO PODER PÚBLICO, INCLUSIVE AOS ESTADOS-MEMBROS - CONFIGURAÇÃO, NO CASO, DE TÍPICA HIPÓTESE DE OMISSÃO INCONSTITUCIONAL IMPUTÁVEL AO ESTADO-MEMBRO DESRESPEITO À CONSTITUIÇÃO PROVOCADO POR INÉRCIA ESTATAL (RTJ 183/818819) - COMPORTAMENTO QUE TRANSGRIDE A AUTORIDADE DA LEI FUNDAMENTAL DA REPÚBLICA (RTJ 185/794-796) - A QUESTÃO DA RESERVA DO POSSÍVEL: RECONHECIMENTO DE SUA INAPLICABILIDADE, SEMPRE QUE A INVOCAÇÃO DESSA CLÁUSULA PUDER COMPROMETER O NÚCLEO BÁSICO QUE QUALIFICA O MÍNIMO EXISTENCIAL (RTJ 200/191-197) - O PAPEL DO PODER JUDICIÁRIO NA IMPLEMENTAÇÃO DE POLÍTICAS PÚBLICAS INSTITUÍDAS PELA CONSTITUIÇÃO E NÃO EFETIVADAS PELO PODER PÚBLICO - A FÓRMULA DA RESERVA DO POSSÍVEL NA PERSPECTIVA DA TEORIA DOS CUSTOS DOS DIREITOS: IMPOSSIBILIDADE DE SUA INVOCAÇÃO PARA LEGITIMAR O INJUSTO INADIMPLEMENTO DE DEVERES ESTATAIS DE PRESTAÇÃO CONSTITUCIONALMENTE IMPOSTOS AO ESTADO - A TEORIA DA "RESTRIÇÃO DAS RESTRIÇÕES" (OU DA "LIMITAÇÃO DAS LIMITAÇÕES") - CARÁTER COGENTE E VINCULANTE DAS NORMAS CONSTITUCIONAIS, INCLUSIVE DAQUELAS DE CONTEÚDO PROGRAMÁTICO, QUE VEICULAM DIRETRIZES DE POLÍTICAS PÚBLICAS, ESPECIALMENTE NA ÁREA DA SAÚDE (CF, ARTS. 196, 197 E 227) - A QUESTÃO DAS "ESCOLHAS TRÁGICAS" - A COLMATAÇÃO DE OMISSÕES INCONSTITUCIONAIS COMO NECESSIDADE INSTITUCIONAL FUNDADA EM COMPORTAMENTO AFIRMATIVO DOS JUÍZES E TRIBUNAIS E DE QUE RESULTA UMA POSITIVA CRIAÇÃO JURISPRUDENCIAL DO DIREITO - CONTROLE JURISDICIONAL DE LEGITIMIDADE DA OMISSÃO DO ESTADO: ATIVIDADE DE FISCALIZAÇÃO JUDICIAL QUE SE JUSTIFICA PELA NECESSIDADE DE OBSERVÂNCIA DE CERTOS PARÂMETROS CONSTITUCIONAIS (PROIBIÇÃO DE RETROCESSO SOCIAL, PROTEÇÃO AO MÍNIMO EXISTENCIAL, VEDAÇÃO DA PROTEÇÃO INSUFICIENTE E PROIBIÇÃO DE EXCESSO) - DOUTRINA - PRECẺDENTES DO SUPREMO TRIBUNAL FEDERAL EM TEMA DE IMPLEMENTAÇÃO DE POLÍTICAS PÚBLICAS DELINEADAS NA CONSTITUIÇÃO DA REPÚBLICA (RTJ 174/687 - RTJ 175/1212-1213 - RTJ 199/1219-1220) - POSSIBILIDADE JURÍDICO-PROCESSUAL DE Revista do Direito UNISC, ISSN: 1982-9957
}

Santa Cruz do Sul №. 48 | p. 92-117 | JAN-ABR 2016

https://online.unisc.br/seer/index.php/direito/index 
Mais do que nunca, é preciso enfatizar que o dever estatal de atribuir efetividade aos direitos fundamentais, de índole social, qualifica-se como expressiva limitação à discricionariedade administrativa. Isso significa que a intervenção jurisdicional, justificada pela ocorrência de arbitrária recusa governamental em conferir significação real ao direito à saúde, tornar-se-á plenamente legítima (sem qualquer ofensa, portanto, ao postulado da separação de poderes), sempre que se impuser, nesse processo de ponderação de interesses e de valores em conflito, a necessidade de fazer prevalecer a decisão política fundamental que o legislador constituinte adotou em tema de respeito e de proteção ao direito à saúde.

(...)

O magistrado, quando aplica a Constituição e obriga os demais poderes a agirem de acordo com a previsão de seu papel constitucional, não está atuando para interferir nos outros poderes, ferindo, assim, o princípio da separação dos poderes, de modo a chamar para si a função política dos demais, mas sim, visa adequar sua conduta às previsões constitucionais realizando sua atribuição de afastar lesões ou ameaças a direito e concretizando os direitos fundamentais.

Assim, diante da obrigatoriedade de ação do Poder Judiciário, decorrente de sua razão de existência - que é dirimir conflitos - de modo a cumprir com a exigência constitucional de afastar lesões ou ameaças de lesão à direito, não há que se falar em ofensa à separação de poderes, grande obstáculo ao reconhecimento da legitimidade do Judiciário para proferir manifestações sobre as decisões políticas do Estado. Portanto, uma vez admitida a possibilidade de intervenção do Judiciário, afastando a tese de sua ilegitimidade, conforme já decidido pelo STF, surge outro questionamento: como se dará essa intervenção? E outros dele decorrentes: de que forma o Poder Judiciário fará cumprir a Constituição no que toca à obrigação do Executivo de aplicar os valores mínimos com gastos em saúde? Poderá ainda obrigar a aplicação de valores em programas ou ações de saúde específicos?

UTILIZAÇÃO DAS "ASTREINTES" (CPC, ART. 461, § 5०) COMO MEIO COERCITIVO INDIRETO - EXISTÊNCIA, NO CASO EM EXAME, DE RELEVANTE INTERESSE SOCIAL AÇÃO CIVIL PÚBLICA: INSTRUMENTO PROCESSUAL ADEQUADO À PROTEÇÃO JURISDICIONAL DE DIREITOS REVESTIDOS DE METAINDIVIDUALIDADE - LEGITIMAÇÃO ATIVA DO MINISTÉRIO PÚBLICO (CF, ART. 129, III) - A FUNÇÃO INSTITUCIONAL DO MINISTÉRIO PÚBLICO COMO "DEFENSOR DO POVO" (CF, ART. 129, II) - DOUTRINA PRECEDENTES - RECURSO DE AGRAVO IMPROVIDO. Recurso Extraordinário- RE 581352/AM. Estado do Amazonas e Ministério Público do Estado do Amazonas. Relator Ministro Celso de Mello. Acórdão eletrônico DJe-230 publicado em 22/11/2013. Disponível em: $<$ http://redir.stf.jus.br/paginadorpub/paginador.jsp?docTP=TP\&doclD=4904100>. Acesso em: 24 nov. 2014.

Revista do Direito UNISC, ISSN: 1982-9957

Santa Cruz do Sul №. 48 | p. 92-117 | JAN-ABR 2016

https://online.unisc.br/seer/index.php/direito/index 
E, se positiva a resposta, como fica a questão do procedimento da elaboração das peças orçamentárias, eis que dependem de aprovação legislativa?

\title{
4. A questão orçamentária
}

Vanice Regina Lirio do Vale (2009, p. 108) reconhece que a atuação do Judiciário reflete uma resposta à atuação do Executivo. Em suas palavras:

\begin{abstract}
A exploração dessa estratégia expressa claramente uma reação do próprio Poder Judiciário à reiterada apresentação do argumento da ausência de orçamento (num plano mais imediato) e da reserva do possível, como bloqueio absoluto a qualquer pretensão concretizadora de direitos fundamentais, sem a indicação sequer de uma remota possibilidade de qualquer mudança futura nesse mesmo cenário de ausência de financiamento.
\end{abstract}

Mais adiante critica decisões que determinam ao poder público prover orçamento, remanejar recurso ou determinar abertura de créditos suplementares asseverando que: "nada mais fazem do que superar, pontualmente, o argumento da ausência de fonte de financiamento".

E arremata afirmando que desconhecem a circunstância de que, uma vez que 'as dotações são limitadas, a destinação de valores a um programa ou ação, evidentemente, significa a diminuição, na mesma proporção do montante destinado a outras atividades desenvolvidas pelo poder Público" (VALLE, p. 110).

No entanto, não se pode afastar as normas constitucionais que estabelecem obrigações no que toca ao tema e esclarecem as atividades que devem executar as diferentes pessoas políticas. Neste sentido, a norma consubstanciada no artigo 23, inciso II, CF/88, dispõe sobre a competência comum da União, dos Estados, do Distrito Federal e dos Municípios cuidar da saúde e assistência pública e o art. 196 CF/88 determina ao Estado garantir esse direito por meio de políticas públicas. Por outro lado, o Estado, através da administração pública, deve prestar os serviços de saúde pautados nos princípios da legalidade, impessoalidade, moralidade, publicidade e eficiência, conforme dispõe o artigo $37 \mathrm{CF} / 88$. Assim, constitui direito de toda pessoa usufruir os serviços públicos essenciais, como é o caso dos serviços de saúde, 
de maneira satisfatória e eficaz, devendo o Estado zelar pela sua execução, tal como versam os dispositivos constitucionais constantes nos artigos 196, 197 e 198 CF/88.

A inobservância dos preceitos constitucionais, independentemente dos argumentos de impossibilidade financeira, deve ser repelida, sob pena de manutenção de um estado de ilegalidade e negativa de direitos aos cidadãos que necessitam da prestação gratuita dos serviços de saúde.

Há ainda que ser refutado o argumento de que há invasão, pelo Poder Judiciário, do âmbito de ação reservado ao administrador pela discricionariedade administrativa. Neste sentido, se o Judiciário determina que o poder público realize um gasto com saúde, invade uma esfera de competência que the é própria. Todavia, há que se perceber que essa prerrogativa não concede ao administrador a possibilidade de optar por permanecer em situação ilegal, ou seja, de não dar cumprimento à legislação aplicável.

Nesse sentido foram encontrados precedentes jurisprudenciais determinando medidas no sentido acima, entendendo a intervenção judicial como uma possível solução para que não se perpetue o descumprimento do comando legal inclusive determinando a inclusão de valores para saúde nos orçamentos públicos. Veja-se o Processo No 0012552-42.2013.4.01.3600 da $3^{\text {a }}$ Vara Federal Mato Grosso onde discutia-se a imediata inclusão na Lei de Diretrizes Orçamentárias e na Lei Orçamentária Anual de 2015 de dotação de recursos necessários e suficientes para finalização da obra do Hospital Central, bem como do novo hospital.

Consta da decisão a seguinte afirmação "entendo que não há violação ao Princípio da Separação dos Poderes em se determinar apenas a inclusão na proposta orçamentária dos recursos suficientes e necessários para finalização da obra do Hospital Central, bem como do novo hospital proposto pelo Estado em uma das diversas tratativas já realizadas nos autos, em busca do melhor meio de se garantir o cumprimento integral da sentença. Trata-se 
apenas de garantir que a proposta será levada à votação, a qual, entretanto, como toda votação do Legislativo, será livre". 10

Logo, a questão orçamentária deve ser vista com ressalvas. Se é certo que o Poder Judiciário, via de regra não deve intervir, por outro lado, não poderá, por determinação constitucional, se calar diante da omissão ou ineficiência dos demais poderes. Parece evidente que se a legislação determina um percentual ou dispõe de critérios que devem ser observados em gastos com saúde, ante a não comprovação destes gastos pelo poder público, o Judiciário não pode se omitir no seu papel de fazer cumprir a Constituição e contribuir para a concretização de direitos fundamentais.

A realidade é farta em exemplos de desvios de dinheiro, corrupção, má administração orçamentária. Logo, o argumento de insuficiência ou limitação de recursos deve ser comprovado para justificar a inobservância da LC 141/2012.

De fato, não se pode impedir a judicialização da saúde especialmente ante o descumprimento legal por parte do poder público. Impedir que o Judiciário intervenha no âmbito da saúde pública causaria o que Ingo Wolfgang Sarlet (2009), ao comentar sobre as ações que pleiteiam o fornecimento de medicamentos, chama de dupla exclusão:

\begin{abstract}
é a exclusão de quem não recebe nem o medicamento que o protocolo, a lei impõe o fornecimento, e a exclusão de que essa pessoa não poderia, então, buscar o Poder Judiciário, seja por via coletiva, seja por via individual. É dupla exclusão do sistema: ou seja, temos que nos conformar a sermos atendidos na medida do sistema existente e não sermos atendidos, ainda que a lei, os protocolos imponham esse atendimento.
\end{abstract}

Em outras palavras, se o poder público não comprovar os gastos com saúde segundo determina a LC 141/2012, poderá o julgador, afastando a teoria da reserva do possível, determinar medidas que assegurem o seu cumprimento não se configurando qualquer irregularidade ou ofensa à teoria da separação dos poderes.

\footnotetext{
${ }^{10}$ TRF1 - Tribunal Regional Federal da 1a Região. Cumprimento provisório de sentença. Processo n0012552-42.2013.4.01.3600. Ministério Público Federal e Estado do Mato Grosso. Juiz Cesar Augusto Bearsi. Decisãopublicada em 03/10/2014. Processo eletrônico.Disponível em:

http://processual.trf1.jus.br/consultaProcessual/processo.php?trf1_captcha_id=e87895aba34e4 1b73cb8583e101482e9\&trf1_captcha $=28 v$ venviar=Pesquisar\&proc $=00125524220134013600$ \&secao=MT. Acesso em: 24 dez.2014.
} 


\section{Considerações finais}

Como já afirmado anteriormente, a saúde é um direito fundamental do ser humano, devendo o Estado prover as condições indispensáveis ao seu pleno exercício. O dever do Estado de garantir a saúde consiste na formulação e execução de políticas econômicas e sociais que visem à redução de riscos e doenças e ao estabelecimento de condições que assegurem acesso universal e igualitário às ações e aos serviços de proteção, defesa, promoção, prevenção, preservação e recuperação da saúde.

No entanto, os dados demonstram que há um déficit enorme em investimentos na área de saúde. Com o objetivo de aumentar os gastos em saúde, foram editadas a EC /2000 e LC 141/2012. Mesmo diante da previsão constitucional, o poder público continua investindo menos em saúde do que determina a lei.

Diante da inobservância legal e da provocação do cidadão através da via judicial, abre-se a possibilidade do Poder Judiciário manifestar-se sobre a questão e de intervenção do judiciário embora a Constituição determine que o direito à saúde deve ser efetivado mediante políticas públicas - notadamente a cargo do Poder Executivo e Legislativo.

A intervenção judicial em matéria de políticas públicas na área de saúde poderá fundamentar-se no descumprimento das Emendas Constitucionais que determinam parâmetros para os gastos públicos com saúde, podendo ainda o julgador determinar medidas para que se incluam nos orçamentos públicos as rubricas necessárias para esta finalidade.

\section{Referências}

ARCIDIÁCONO, Pilar; GAMALLO, Gustavo. Política social y judicialización de los derechos sociales. Revista Temas y Debates. ISSN 1666-0714, año 15, número 22, julio-diciembre 2011, pp. 65-85. Disponível em: $<$ http://rephip.unr.edu.ar/bitstream/handle/2133/2594/Arcidi\%C3\%A1cono.pdf?s equence=1>. Acesso em: 13 fev. 2016. 
BARBOSA, Claudia Maria. A legitimidade do exercício da jurisdição constitucional no contexto da judicialização da política. In: BARRETO, V.; DUARTE, F.; SCHWARTZ, G. Direito da sociedade policontextural. Curitiba: Appris, 2013. p. 171-193.

BRASIL. Ministério do Meio Ambiente. Disponível em: <http://www.mma.gov.br/estruturas/agenda21/_arquivos/consulta2edicao.pdf>. Acesso em: 01 dez. 2014.

Ministério da Saúde. Emenda Constitucional no 29: um avanço significativo para 0 setor da saúde. s/d. Disponível em: <http://conselho.saude.gov.br/ultimas_noticias/2005/ec29.htm>. Acesso em: 24 nov. 2014.

TCU -Tribunal de Contas da União. Relatório sistêmico de fiscalização da saúde - FISC SAÚDE. 2013. Disponível em: <http://portal2.tcu.gov.br/portal/page/portal/TCU/imprensa/noticias/noticias_arq uivos/032.624-2013-1\%20Fisc\%20Saude.pdf>. Acesso em: 24 dez. 2014.

CAMPELLI, Magali Geovana Ramlow; CALVO, Maria Cristina M. O cumprimento da Emenda Constitucional №. 29 no Brasil. Caderno Saúde Pública vol. 23 n.7 Rio de Janeiro Jul. 2007. Disponível em: $<$ http://www.scielosp.org/scielo.php?script=sci_arttext\&pid=S0102311X2007000700012\&lng=pt\&nrm=is 2>. Acesso em 24 nov. 2014.

CARRIL, Enrique Del. Os direitos sociais como anomalias. Reflexões em torno da justiciabilidade dos direitos econômicos, sociais e culturais no sistema interamericano. Revista Quaestio luris, vol.04, ㄲo01. Disponível em: $<$ http://www.e-

publicacoes.uerj.br/index.php/quaestioiuris/article/view/10205/7983>. Acesso em 24 jan. 2016. 
CFM - CONSELHO FEDERAL DE MEDICINA. Após três anos, governo conclui apenas $11 \%$ das ações em saúde. Disponível em: http://portal.cfm.org.br/index.php?option=com content\&view=article\&id=24589: apos-tres-anos-governo-conclui-apenas-11-das-acoes-em-saude\&catid=3. Acesso em 01 dez. 2014.

CFM - CONSELHO FEDERAL DE MEDICINA. Saúde representa só 8\% do total dos investimentos públicos do Brasil. Disponível em:<http://portal.cfm.org.br/index.php?option=com_content\&view=article\&id=24 511:saude-representa-so-8-do-total-de-investimentos-publicos-nobrasil\&catid=3>. Acesso em: 23 nov. 2014.

CNS - CONSELHO NACIONAL DE SAÚDE. Cofin apresenta relatório sobre auditorias realizadas pelo DenaSUS. Disponível em:http://conselho.saude.gov.br/ultimas noticias/2010/12 ago confin relaudito ria.htm. Acesso em 24 nov. 2014.

ENSP - Escola Nacional de Saúde Pública Sergio Arouca. Disponível em: <http://www.ensp.fiocruz.br/portal-ensp/informe/site/materia/detalhe/29136>. Acesso em: 01 dez. 2014.

HACHEM, Daniel Wunder. A dupla titularidade (individual e transindividual) dos direitos fundamentais econômicos, sociais, culturais e ambientais. Revista de Direitos Fundamentais e Democracia, Curitiba, v. 14, n. 14, p. 618-688, julho/dezembro de 2013.2 Disponível em: <apps.unibrasil.com.br/ojs235/index.php/rdfd/article/download/.../377>. Acesso em: 13 fev. 2016.

HIRSCHL, Ran. The new constitutionalism and the judicialization of purê politics worldwide. 75 Fordham L. Rev. 721 (2006-2007),Fordham Law Review Vol:75 pp:721-754. 
LANGFORD, Malcolm. Judicialização dos direitos econômicos, sociais e culturais no âmbito nacional: uma análise socio-jurídica. Sur, Revista internacional direitos humanos, São Paulo , v. 6, n. 11, p. 98133, Dec. 2009.

Disponível em:

<http://www.scielo.br/scielo.php?script=sci_arttext\&pid=S1806-

64452009000200006\&lng=en\&nrm=iso >. Acesso em: 13 fev. 2016.

NATAL, Mariane; PAMPLONA, Danielle Anne. O papel político do judiciário em políticas públicas: a judicialização da política e a democracia, Revista Direito Mackenzie, v. 8, n.1 (2014), p. 128/140.

OLSEN, Ana Carolina Lopes. A eficácia dos direitos fundamentais sociais frente à reserva do possível. Dissertação de mestrado, UFPR 2006. Disponível em:<http://dspace.c3sl.ufpr.br/dspace/bitstream/handle/1884/3084/Disserta\%20 $\% 200++$ Ana+Carolina+Lopes+Olsen.pdf?sequence=1>. Acesso em: 24 nov. 2014.

ONU - Organização das Nações Unidas. Conferência sobre Meio Ambiente e Desenvolvimento. Disponível em $<$ https://www.google.com.br/url?sa=t\&rct=i\&q=\&esrc=s\&source=web\&cd=1\&ve d=0CCAQFjAA\&url=http\%3A\%2F\%2Fwww.mma.gov.br\%2Festruturas\%2Fage nda21\%2F arquivos\%2Fcap06.doc\&ei=QTGbVYllsWpwgSOur ACw\&usg=AF QjCNFRwnDNYK nALuT46V9boe VgNXbRw\&bvm=bv.96952980,d.Y2l>, Acesso em 20 nov. 2014.

PAMPLONA, Danielle Anne; ANDRADE, Manoela Moreira de. O controle constitucional de políticas públicas no Supremo Tribunal Federal. Revista Eletrônica Direito e Política, Programa de Pós-Graduação Stricto Sensu em Ciência Jurídica da UNIVALI, Itajaí, v.6, n.3, 3o quadrimestre de 2011. Disponível em: <www.univali.br/direitoepolitica - ISSN 1980-7791>. Acesso em 27 ago. 2014. 
PEREIRA, Delvechio de Souza. 0 orçamento público e o processo de Judicialização da saúde. Disponível em: <http://portal2.tcu.gov.br/portal/pls/portal/docs/2055752.PDF>. Acesso em: 24 nov. 2014. p. 7

PIOLA, Sergio Francisco, et al. Estruturas de financiamento e gasto do sistema público de saúde. Fundação Oswaldo Cruz. A saúde no Brasil em 2030 - prospecção estratégica do sistema de saúde brasileiro: estrutura do financiamento e do gasto setorial [online]. Rio de Janeiro: Fiocruz/Ipea/Ministério da Saúde/Secretaria de Assuntos Estratégicos da Presidência da República,2013. Vol. 4. pp. 19-70. Disponível em:<http://books.scielo.org/id/z9374/pdf/noronha-9788581100180-03.pdf>. Acesso em: 01 dez. 2014.

PIOVESAN, Flavia. Direitos sociais, econômicos e culturais e direitos civis e políticos.Sur, Revista internacional de direitos humanos., São Paulo , v. 1, n. 1, p. 20-47, 2004 . Disponível em: $<$ http://www.scielo.br/scielo.php?script=sci_arttext\&pid=S180664452004000100003\&lng=en\&nrm=iso >. Acesso em: 13 fev. 2016.

SARLET, Ingo Wolfgang. Pronunciamento na audiência pública da saúde no STF. 2009.2 Disponível em: <http://www.stf.jus.br/arquivo/cms/processoAudienciaPublicaSaude/anexo/Sr._I ngo_Sarlet_titular_da_PUC_.pdf>. Acesso em: 24 nov. 2014.

SILVA, Christian Luiz da Silva e ROTTA, Cristiano Vieira. O dilema da universalidade e financiamento público do Sistema Único de Saúde no Brasil. Textos \& Contextos (Porto Alegre), v. 11, n. 2, p. 333 - 345, ago./dez. 2012.

Disponível em: $<$ http://revistaseletronicas.pucrs.br/ojs/index.php/fass/article/viewFile/12126/864 2>. Acesso em: 24 nov. 2014. 
SILVA, Maurício Corrêa da Silva, João HalbertoBalduino Maciel, Márcia Josienne Monteiro Chacon, Aneide Oliveira Araujo. Gastos com Saúde: uma Análise do Cumprimento da Emenda Constitucional no 29/2000 pelos 100 municípios brasileiros mais populosos, no período de 2000 a 2008. REUNIR Revista de Administração, Contabilidade e Sustentabilidade - Vol. 2, no1, p.120, Jan-Abr/2012. Disponível em: <http://150.165.111.246/revistaadmin/index.php/uacc/article/download/31/54>. Acesso em: 24 nov. 2014.

SOUZA, Celina. Políticas públicas: uma revisão da literatura. In Sociologias. n. 16. Porto Alegre jul./dez. $2006 . \quad$ Disponível em:<http://www.scielo.br/scielo.php?script=sci_arttext\&pid=S1517$45222006000200003 \&$ lng=pt\&nrm=iso\&userlD=-2>. Acesso em: 25 ago. 2014.

TAYLOR, Matthew M. 0 judiciário e as políticas públicas no Brasil. Dados. vol.50 no 2 Rio de Janeiro, 2007. Disponível em: $<$ http://www.scielo.br/scielo.php?script=sci_arttext\&pid=S0011 52582007000200001>. Acesso em: 27 ago. 2014.

VALLE, Vanice Regina Lírio do. Políticas públicas, direitos fundamentais e controle judicial. Belo Horizonte, Editora Forum, 2009.

VALLINDER, Torbjörn; TATE, Chester Neal. The Global Expansion of Judicial Power: The Judicialization of Politics. New York, New York University. 1995.

VIANA, Ana Luiza D'Ávila e MACHADO, Cristiani Vieira Machado. Proteção social em saúde: um balanço dos 20 anos do SUS. Physis vol.18, no.4 Rio de Janeiro 2008.

Disponível

em:

<http://www.scielo.br/scielo.php?script=sci_arttext\&pid=S0103-

73312008000400004>. Acesso em: 01 dez. 2014.

Referência de jurisprudência 
BRASIL.Superior Tribunal de Justiça - STJ. Agravo Regimental no Recurso Especial no 1107511. Julgamento em 06.12.2013. 2013a. Disponível em: <https://ww2.stj.jus.br/processo/revista/documento/mediado/?componente=ATC \&sequencial $=32518375 \&$ num_registro $=200802653389 \&$ data $=20131206 \&$ tipo $=5$ 1\&formato=PDF>. Acesso em: 24 nov. 2014.

Supremo Tribunal Federal - STF. Arguição de descumprimento de preceito fundamental - ADPF 45/DF. Relator Min. Celso de Mello. DJ 04/05/2004. Revista Trimestral de Jurisprudência - RTJ - vol. 200, p. 191.Disponível

em: $<$ http://www.stf.jus.br/portal/jurisprudencia/listarJurisprudencia.asp?s1=\%28AD PF\%24\%2ESCLA\%2E+E+45\%2ENUME\%2E\%29\&base=basePresidencia\&url= http://tinyurl.com/a9kzfpa>. Acesso em: 24 nov. 2014.

. Supremo Tribunal Federal - STF. Recurso Extraordinário- RE

581352/AM. Relator Ministro Celso de Mello. Acórdão eletrônico DJe-230 publicado em 22/11/2013. 2013b. Disponível em:<http://redir.stf.jus.br/paginadorpub/paginador.jsp?docTP=TP\&docID=4904 100>. Acesso em: 24 nov. 2014.

. Tribunal Regional Federal da 1를 Região. TRF1 - Tribunal Regional Federal da 1a Região. Cumprimento provisório de sentença. Processo no0012552-42.2013.4.01.3600. Ministério Público Federal e Estado do Mato Grosso. Juiz Cesar Augusto Bearsi. Decisão publicada em 03/10/2014. Disponível em: <http://www.midianews.com.br//storage/webdisco/2014/10/06/outros/0976fe436 cb785e738e749b0219b8580.pdf>. Acesso em: 24 dez.2014. 